International Journal of Linguistics, Literature and Translation

ISSN: 2617-0299 (Online); ISSN: 2708-0099 (Print)

DOI: 10.32996/ijltt

Journal Homepage: www.al-kindipublisher.com/index.php/ijltt

IJLLT

\title{
Swearing Using Body Parts in the Jordanian Setting: A Socio-Pragmatic Analysis Faculty of Educational Sciences and Arts (UNRWA)
}

\author{
Dr. Sameer Hamdan ${ }^{1}$ 8(D) $\triangle$ and Dr. Omar Abdullah Al-Haj Eid² 8(D) \\ ${ }^{7}$ Assistant Professor of Curriculum \& Methodology (English), Faculty of Educational Sciences and Arts (UNRWA), Jordan \\ ${ }^{2}$ Assistant Professor of Linguistics, Faculty of Educational Sciences and Arts (UNRWA), Jordan
}

$\triangle$ Corresponding Author: Dr. Omar Abdullah Al-Haj Eid, E-mail: O.el- hajeid@unrwa.org

\begin{tabular}{|c|c|}
\hline ARTICLE INFORMATION & ABSTRACT \\
\hline $\begin{array}{l}\text { Received: July 08, } 2021 \\
\text { Accepted: September 01, } 2021 \\
\text { Volume: } 4 \\
\text { Issue: } 9 \\
\text { Dol: } 10.32996 / \text { ijllt.2021.4.9.5 }\end{array}$ & $\begin{array}{l}\text { The study aimed to identify swearing using body parts in the Jordanian setting as a } \\
\text { social phenomenon used by male university students. The corpus of the study } \\
\text { included (100) male university students. A socio-pragmatic approach was adopted to } \\
\text { analyze the data. The study employed Simak Libat Cakap technique in addition to the } \\
\text { qualitative method to analyze the data of the study. The analysis of data showed that } \\
\text { the face was the most frequent body part used in swearing followed by the head. The }\end{array}$ \\
\hline KEYWORDS & main findings revealed that swearing is dominantly used to express a socio-pragmatic \\
\hline $\begin{array}{l}\text { Swearing, swearers, disputers, } \\
\text { socio-pragmatic, body parts, } \\
\text { angriness }\end{array}$ & $\begin{array}{l}\text { Swearing functions as a vehicle for releasing tension and anger and proved to be } \\
\text { powerful in exchanging insults. The study concluded that swearers usually do not } \\
\text { mean what they say. Swearing mostly includes non-literal meanings like idioms. } \\
\text { Therefore, it should not be interpreted literally; otherwise, it will lose its connotative } \\
\text { meaning. }\end{array}$ \\
\hline
\end{tabular}

\section{Introduction}

The use of courteous language as a means of communication reflects the community's identity, linguistic behavior, and social background. People use standard and vernacular language in their daily life communication. They could not be well-mannered all the time. In some cases, people resort to taboo or swear words while speaking in public for a variety of reasons to achieve certain sociolinguistic functions. Swearing is widely used in the world and all languages. Anggita (2015) and Taufiq (2017) studied in depth the sociolinguistic functions and causes of using swearing in daily interactions in public as a current trend nowadays by community members. Therefore, swearing which is prevalent nowadays, has become universally in existence. Although it is part and parcel of human's linguistic repertoire abounding in every society, it is strictly condemned in conservative societies because it is against the society's religious, moral and cultural values. It is deemed obscene, vulgar, and impolite language and is socially unaccepted by many people. Montagu (2010) confirmed that the use of swearing is socially denounced though it is used at home and other places. It is depicted as obscene language which is rejected.

Swearing is, on the other hand, used in different ways by different societies around the globe. Some societies use obscene language in swearing, and they are not decent in swearing because they use taboo words. However, Arab countries are unlike any other liberal European ones on the issue of swearing. They are decent and conservative in using swearing. Montagu (ibid., 2010) argued that Asian societies, especially Arab societies are conservative due to their culture. Such societies stigmatize anyone using swear words. In Jordan, swearing is commonly used in the formal setting, but is also disapproved by society as it violates its social norms and code of conduct. Swearing in public is also forbidden by law and is considered a crime in Jordan.

The problem of study is related to swearing using body parts. The problem formation can be illustrated as what body parts are used in swearing and the socio-pragmatic functions used in swearing in the microcosm of the Jordanian university student. A socio-pragmatic approach was adopted to analyze the data. The study employed Simak Libat Cakap technique and qualitative

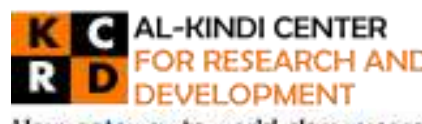

Your gateway to world-class research

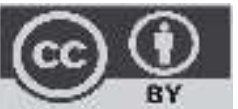

Published by Al-Kindi Center for Research and Development, London, United Kingdom. Copyright (c) the author(s). This open access article is distributed under a Creative Commons Attribution (CC-BY) 4.0 license 
method to analyze the data of the study. It limits itself to a socio-pragmatic analysis of swearing using body parts in the Jordanian setting by male university students.

\section{Literature Review}

\subsection{Related Studies}

Different research studies related to the study problem of this paper can be classified as socio-pragmatic studies. Baudin (ibid., 2014) examined swearing in English among (51) female teenagers in the Malaysian setting and found out that swearing is a normal phenomenon though it is strictly rejected by society. The study also investigated the reasons why teenagers practice swearing. It showed that Malaysian teenagers frequently use the swearwords: hit, damn, and hell followed by bitch, fuck and bullshit. The findings revealed that swearing functions as a medium of daily life communication. The study also confirmed that swearing is done among girlfriends and hardly ever among male friends, outsiders, parents, and teachers. Unlike Baudin (2014), Setiawan and Fatimatuzzahroh (2018) investigated swearwords among Indonesian males focusing on their social functions and pragmatic meanings. The qualitative study illustrated that swear words which include taboo words, express emotions and negative meanings. However, Indonesian males express social functions such as intra individual and inter-individual revealed into cathartic, offensive, resounding, idiomatic and swearing. Moreover, the study concluded swear words are pragmatically bound by context voice the swearer's anger. The study also concluded that Indonesian male swearing acts as a gentle caution on the impact of what one produces and a wise interpretation upon one produces. Jay and Janschewitz (2008) examined swearing in a different context. Their study sample included native and non-native English-speaking college students rating the impoliteness and possibility of hypothetical scenarios involving taboo words. The study results confirmed that the appropriateness of swearing is contextually changeable. The study explained that swearing is pragmatically used to express the emotions of angriness and frustration. In another context, Susetyaningsih (ibid.,2014) discussed swearing uttered by the main character in the film "The Wolf of Wall Street". The writer used a data sheet as an instrument to write down swear words said by the film characters. The study demonstrated that swearing in the film is categorized into four types: expletive, abusive, humorous and auxiliary swearing, which is the preferred swearing type in the film and is linguistic causes concerning the social contexts in the film. Meanwhile, Oliver (2011) examined swearing in classroom as a phenomenon neglected in classrooms in Iceland. The qualitative study intended to explore teachers' attitudes and approach towards lessons about swearing and proper language used in EFL classrooms in Iceland. The research studied the sociolinguistics of swearing by examining taboo language, he investigated the relationship between language and culture. The study concluded that teachers responded differently to swearing used inside classrooms. Some teachers were ignorant of it; meanwhile, others were oversensitive to swearing. Moreover, the study concluded that teachers' reaction to swearing relies on various factors such as culture, values, and style of teaching.

\subsection{Swearing}

Swearing as a sociolinguistic term is considered as a medium of communication to express people's behavior ,emotional feelings, thoughts and what is going in their minds. It also expresses ill-mannered language which necessitates shameful and profane words described as socially and culturally banned in the Jordanian community. Andersson and Trudgill (1990) defined swearing as a type of language referring to taboo and/or stigmatized words in culture and should not be interpreted literally; it can be used to express strong feelings and attitudes, (quoted in Baudin: ibid:2014). The aforementioned definition explains the criteria on which swearing can be judged. Another definition, swearing refers to "a rude or offensive word used, for example, to express anger. Swearing typically incorporates bad, taboo, abusive and filthy words,( Oxford Learner's Dictionary, 2001). In Wikipedia (2015), swearing refers to the use of abusive, bad, rude, offensive, blasphemous, or coarse language. It is also synonymous with dirty, vulgar, expletive, profane ,curse or disrespect words. On the other hand, Rassin and Muris (2002) defined swearing as taboo words in the content that can be used in religion, sex, insanity, body parts and body functions ( quoted in Susetyaningsih, 2014). Similarly, Pinker (2010) defined swearing as the use of impolite words, taboo words referring to animals, religion, gender and body parts such as sexual organs to express resentment, displeasure, pain and /or frustration. Although this linguistic phenomenon includes obscene words, it is commonly used in public around the world and in the Jordanian community nowadays, especially at schools, universities, social gatherings, in the street and other government institutions. Finally, swearing using body parts can be used to convey several meanings and socio-pragmatic functions based on the situation, social context, motive and participant. Holmes (2013) confirmed that swearing conveys several functions according to the social context such as annoyance, hostility, and offense. It may also convey other sociolinguistic functions such as friendliness and solidarity.

\subsection{Theoretical Framework on Swearing}

With the aim of investigating swearing using body parts in the Jordanian Setting, the researchers adopted the sociolinguistic theory to account for the phenomenon of swearing using body parts in the Jordanian Setting. 


\subsubsection{Sociolinguistic Theory}

The sociolinguistic theory is related to language theories concerning the relationship between language and society. Sociolinguistics is the study of language with respect to the social setting employed in society (Hudson, 1996).The term is also endeavored to examine the connection between language and community. It is interested in studying taboo language with regard to the social context and gender, politeness, age, culture, behavior, and attitudes of the speaker. In other words, it attempts to observe how socio-cultural conventions are revealed in language. with reference to gender and socio-cultural conventions there are differences in using swear language between male and female university students as they talk in different ways regarding utterances and choice of words. Holmes (2001) argued that the linguistic forms used by men and women differ in all speech communities due to socio-cultural conduct. She carried on females are well-mannered than males and both of them use language differently. The language used by women is depicted as super-polite variety such as euphemisms, indirect requests and free of using swear words (Holmes,2001). Sociolinguists argued that several motives affect human speech communities such as age, gender, and the socio-cultural motives behind this sociolinguistic phenomenon. several researchers agreed with Holmes' point of view that females are politer than males such as Tannen (1990) and Brown and Levinson (1978) who underlined that both genders use language differently due to their socio-cultural conduct.

\section{Aims and Research Methodology}

This present research adopted a qualitative method to examine swearing using body parts by Jordanian university students. This type of method is consistent with the aims of this current paper as it reveals swearing using body parts in society and the reasons behind this sociolinguistic phenomenon. Swearing reflects the social, cultural and educational distinctiveness of the society. Qualitative method takes advantage of the social, cultural and, norms and specificity of the society,(Vanderstoep and Johnston, 2009).

This paper studied in-depth the different body parts used in swearing and their socio-pragmatic functions served by swearing. It also investigated the motives lurking behind this sociolinguistic phenomenon. This study sought to answer the following questions:

1. What body parts do you commonly use in swearing?

2. Why do you usually resort to swearing?

3. Do you mean what you say?

\subsection{Sample and data collection and analysis methods 3.1.1 Sample and data collection.}

Three techniques were adopted in collecting the study sample: note-taking, recording and Simak Libat Cakap technique, which is based on observing the conversation. Sudaryanto (1992) explained that this technique is of great importance for researchers as it enables them to obtain data through listening and taking notes.

The researchers, with the aid of five male university students collected the raw source of data. The steps of data collection were as follows: the five students and researchers met students in university facilities, listened to them attentively, recorded their conversations and took notes of what they said. Students were given two options, either a questionnaire or recording their responses to the questionnaire questions. A questionnaire was devised to analyze the data to see the most frequent body parts used in swearing as well as the motives behind swearing. It consisted of three questions: body parts used in swearing, motives of swearing and whether respondents mean by what they swear or not. See Appendix(A) for the questionnaire.

All the respondents were males since swearing employing body parts are usually made by males in Jordan; meanwhile, females rarely perform such type of swearing and reluctantly refrained from responding to the questionnaire. The respondents were requested to answer the questions of the questionnaire in Arabic. (See appendix (A))

\subsubsection{Data analysis}

Following the data collection procedures, the researchers had the primary data ready for analysis. The relationship between the process of collecting data and analyzing data is indivisible, Bungin (2007). The researchers adopted a qualitative method to examine swearing using body parts and reasons behind swearing by university male students. The source of data in this paper included swearing words articulated by one hundred male university students. All of them were selected from Jordanian universities. Having had the primary data, the researchers firmly classified and compared them regarding their frequencies and percentages. The data were tabulated to show their socio-pragmatic functions and to arrive at the conclusions. A sociopragmatic approach was used to analyze students' questionnaire and recording. 


\section{Result and discussion}

The corpus of the study consisted of (19) body parts and (125) swearing utterances. The results showed that swearing in the Jordanian setting is determinedly used and conveys socio-pragmatic functions. Body parts used in swearing are stated in their percentages and frequencies, as shown in Table (1). They are coded as follows in a descended order from the highest to the least recurrent body parts found in the corpus: face $16.8 \%$ head $12 \%$, mouth $11.2 \%$, eye 11.2 , neck 6,4\%, ear6,4\% , teeth 4\% , mustache $4 \%$,belly 3.3 , hands 3,2\%, tongue3,2\%, head hair 3,2\%, beard 3,2\%, throat $2,4 \%$, nose $2,4 \%$, legs $2,4 \%$, eyebrows $1,6 \%$, eyelashes $1,6 \%$, lips $8 \%$.

Table (1). The Frequency and percentage of Swearing Used in Body Parts

\begin{tabular}{|l|l|l|l|}
\hline No & Body part & Frequency & Percentage \\
\hline 1 & Face & 21 & $16.8 \%$ \\
\hline 2 & Head & 15 & $12 \%$ \\
\hline 3 & Mouth & 14 & $11.2 \%$ \\
\hline $\mathbf{4}$ & Eyes & 14 & $11.2 \%$ \\
\hline $\mathbf{5}$ & Neck & 8 & $6.4 \%$ \\
\hline $\mathbf{6}$ & Ears & 8 & $6.4 \%$ \\
\hline $\mathbf{7}$ & Teeth & 5 & $4 \%$ \\
\hline $\mathbf{8}$ & Mustache & 5 & $4 \%$ \\
\hline $\mathbf{9}$ & Belly & 5 & $4 \%$ \\
\hline $\mathbf{1 0}$ & Hands & 4 & $3.2 \%$ \\
\hline $\mathbf{1 1}$ & Tongue & 4 & $3.2 \%$ \\
\hline $\mathbf{1 2}$ & Head Hair & 4 & $3.2 \%$ \\
\hline $\mathbf{1 3}$ & Beard & 4 & $3.2 \%$ \\
\hline $\mathbf{1 4}$ & Throat & 3 & $2.4 \%$ \\
\hline $\mathbf{1 5}$ & Nose & 3 & $2.4 \%$ \\
\hline $\mathbf{1 6}$ & Legs & 3 & $2.4 \%$ \\
\hline $\mathbf{1 7}$ & Eyebrows & 2 & $1.6 \%$ \\
\hline $\mathbf{1 8}$ & Eyelashes & 2 & 1.6 \\
\hline $\mathbf{1 9}$ & Lips & 1 & $0.8 \%$ \\
\hline Total & 125 & $100 \%$ \\
\hline
\end{tabular}

Table (1) answers the first question of the research regarding the body parts commonly used in swearing. It is obvious from Table (1) that the face ranked first recording the highest frequency (15) and with a percentage of (16.8\%). This high frequency may be attributed to the fact that the face represents one of the most dominant parts of the human body in the culture of the Arabs. It expresses an individual's dignity, appearance, and identity. It is also important in nonverbal communication. Historically, poets, novelists, story writers, and playwrights have given special attention to the face in their writing., Robert Browning, for example, wrote a poem in the name of "A Face". In the Islamic religion , the face is dealt with sacredness. Therefore, hitting someone in their face is strictly prohibited. Prophet Mohammed, peace be upon him, said :"if you hit, avoid the face." Accordingly, it is not surprising that the face recorded the highest frequent occurrence in the corpus. Seething with anger, Jordanians resort first to the face to cause untold harm to their enemies or disputers. I should be noted that the face includes other parts such as lips, mouth, teeth, moustache, eyebrows, eyelashes, and beard. In this case, the swearer firmly believes that other parts are implicitly contained in swearing. Pragmatically speaking, swearers say one thing and mean another.

The head came in the second rank, forming (12\%) of the data. The face and the head are the most important body parts used in swearing by the Jordanian university student. They roughly represent one-quarter of the whole entity of the study sample. Utterances used in swearing ranged from "stepping on your head to cutting your head " .In the Jordanian setting, "stepping on the head by the leg" is deemed more harmful than cutting the head since stepping on the head makes someone lose their dignity and self-respect, which is more insulting than cutting their head, albeit unachievable in most cases. The swearer does not mean it literally, but he means to degrade the disputer. "Stepping on the head" is scarcely ever achievable because of using a lower- body part (the leg) to step on the highest part( head), which is a clear indication of insult.

The mouth is also of great importance as it occupied the third rank with the percentage of (11,2\%) as shown in Table(1). The mouth plays a great role in the beauty of the individual. Facial expressions and forming words are materialized by the mouth. It also includes other internal parts such as teeth, lips, throat and the tongue. It is remarkable that swearers use the mouth as a medium to slur and threaten disputers by saying "I will spit into your mouth."Although the liquid of spitting is considered unpleasant in both form and taste in case of dispute, it is tasteful and aromatic like the taste of honey in case of love albeit with 
the same liquid of spitting. This is the pragmatic use of such words in the Arabic culture where meaning is wholly changed when setting and participants are changed.

The eyes and the mouth are precisely equal occupying the same rank with the percentage of (11.2\%). The eyes are our window to the world. Religiously speaking, the eyes are by far the most blessable organ granted to mankind by God. In the legacy of Arabic poetry from the pre-Islamic period until today, it is rare to find a poem free of describing the beauty of the eyes. Quoting one of the greatest Iraqi poets in the Arabic literature depicting a real portrait of the eye, Badir Shaker Al-Sayyab, in his poem entitled "The Rain Poem", he says, "Your eyes are two palm tree forests at the daybreak before the sun shines....etc". Paradoxically, the most insulting words are those related to the eyes, especially when a swear user quarrels with a person, saying "I will pop your eyeballs out". The quarreler usually does not mean it. It is used figuratively for threatening purposes because the eyes are one of the most valuable organs to mankind.

To be more insulting, Jordanian swearers use plural instead of singular of "eye" to inflect both physical and psychological harm to the quarreled person, especially when the disputer reiterates the awful behavior more than once.

The neck occupied the fourth rank and stood for ( $6.4 \%)$ of the total number of the corpus collected. The neck holds the head and separates the body. Poets in classical Arabic poetry commended the long neck and compared it with the female camel because it shows the charms of a woman. Quoting Imru' Al-Qays, a pre-Islamic poet compares his beloved long neck with an oryx, whose neck is long, saying, "No jewels does her fine slender neck bear. It is oryx-like; it is beautifully white and bare."

The ears also occupied the same rank and percentage (6.4\%). Threatening ranges from cutting to stepping the neck, the same threatening can be applied to the head. Likewise, both the ears and eyes can be used either in plural or singular. Using the plural is highly emphatic and insulting. Cutting both ears indicates that the victim is reiterating the same morally wrong behavior. Cutting one ear is a warning sign not to repeat the undesirable behavior.

The teeth, moustache, and belly also occupied the fifth rank with the percentage of (4\%). It is remarkable that "teeth" remained the same in the plural and excluded the singular use of "teeth". Maybe, it is difficult to hurt somebody by breaking only one tooth. So, when there is growing anger between the quarreler and the quarreled person, Jordanians swear, "I will break your teeth" but not your tooth. Pragmatically speaking, breaking one tooth is unattainable and may not be harmful. On the contrary, breaking more than one tooth in the Jordanian culture is achievable and is more harmful.

Although the hair of moustache is uncountable in English, it is countable in Arabic and is contemptuously used in Arabic in both singular and plural."I will pluck out your mustache hair by hair", is a typical utterance used by a swearer. It is considered more insulting than saying "I will pluck your mustache."Meanwhile, the belly is a different issue. Pre-Islamic poets liked the belly and some of them flirted the belly as it shows the beauty of a woman. Nowadays, some Jordanians consider the full belly as a state of elegance and gracefulness. Having "a big potbelly" denotes that a person lives in luxury. In swearing, "Belly" collocates with the word "stepping" such as "I will step on your belly". This statement is used for insulting purposes. By doing so, other unseen parts of the belly such as the kidney, the liver, the lungs, and the heart are implicated by the process of stepping on the belly ,but not overtly mentioned.

The hand, tongue, hair head and the beard ranked sixth with the percentage of (3.2\%). In this regard, swearers concentrate on breaking one hand or both hands. The difference between the use of singular and plural is attributed to the setting and the degree of anger. The hair of the head is a source of beauty. Bald people are stigmatized by a large segment of Jordanians. That is why swearers try to hurt the disputed individual by saying, "I will pluck your hair out hair by hair." Singularity enables swearers to express their extreme anger compared to using hair as a whole. The hand is not undervalued by swearing users who vow to cut the victim's hand using either singular or plural based on the fault committed by the disputer.

The tongue is an important organ used in praising and cursing."I will cut your tongue." or "I will take your tongue out of your mouth." are good examples uttered to the offended person.

For many Muslims, the beard has religious allusions to the followers of Prophet Mohammed, peace be upon him, who are longbearded. Moreover, it has connotations of dignity, reverence, and wisdom in the Arabic culture. Thus, it is scornful to say to someone, "I will pluck out your beard hair by hair. " or "I will step on your beard." Such action physically, spiritual as well as emotionally affects the victimized person and relentlessly hurts him.

The throat, nose, and legs represented the seventh rank with a percentage of (2.4\%). It is surprising for the legs to be the least frequent occurrence among the body parts. Although the legs are the biggest body part, they are barely used by swearers. They can use them easily to fulfill their threatening immediately. What compensates this meager number of frequency and percentage is the double usage of swearing concerning legs by using them as a tool to harm other parts. This is evident when a swear user 
says, "I will step on your head, face, mustache, beard, mouth, and nose. The word "stepping" contains an implicit use of the foot and /or feet, which are part and parcel of the legs.

Eyebrows and eyelashes stand for the eighth rank with the percentage of (1.6\%).Swearers found it difficult to deal with such type of hair compared with the hair of the head or the beard. Swearers seem reluctant to use such body parts except for a few cases. Swearing by using eyebrows and eyelashes may not cause much harm to the insulted person.

The least frequent body part appeared in the data is the lips with the percentage of (.,8\%). It seems that the lips are not accounted for by swearing users in the Jordanian community. Meanwhile, the mouth that ranked third could be understood as a major body part because it includes the teeth, the tongue, and the throat. See Appendix(B) for illustrative examples of swearing using body parts.

The analysis of the questionnaire confirmed all the (100) respondents resort to swearing when they feel angry with their disputers. They claimed that under such conditions they look for the most offensive words to hurt spiritually and psychologically the insulted person. This answers the second question of the research concerning the motives lurking behind resorting to swearing. The process of insulting occurs, by and large, in the presence of people and is done in trembling voices with fury. It should be noted that swearing is culture-bound and is typically affected by the individual's socio-economic background.

Respondents revealed that they rarely resort to swearing when they are not in a face-to-face setting with the one who causes their angriness. This ensures that angriness is the major source of swearing. Pragmatically speaking, (72) of the respondents with the percentage of $(72 \%)$ claimed that they do not mean what they say. Meanwhile, the (28) respondents with a percentage of (28\%) claimed that they mean what they say and could fulfill their swearing if others prevented them. The overwhelming majority of swearers do not literally mean what they swear except for very few swear users who literally mean it. On the whole, swearing contains figurative meanings such as threatening and insulting. Swearers only use swearwords to alleviate their tension caused by anger and arouse the offended person's resentment. This answers the third question of the research regarding whether the swearers literally mean by what they swear.

\section{Conclusion}

On the basis of the aforementioned results and discussion, the study showed that the face was the most frequent occurrence of the body part used by swearers recording the highest frequency (15)and with a percentage of (16.8\%) because it is one of the most essential body parts in the Jordanian setting followed by the head forming (12\%) of the data. Both the face and head are commonly used by university students in the Jordanian context. The lip was the least frequency (1) with the percentage of $(0.8 \%)$. It is not used in swearing in the Jordanian setting. Swearing body parts is purposefully used to serve a socio-pragmatic function of anger, especially when swearers feel angry with their disputers. It functions as a vehicle for releasing tension and anger since swearing is powerful in exchanging verbal abuse. In support of this socio-pragmatic function of anger, Ljung (2011), Setiawan and Fatimatuzzahroh (ibid., 2018) as well as Jay and Janschewitz (ibid., 2008) highly emphasized that swearing is dominantly used by swearers to express the function of angriness. Swearers do not mean what they say. Swearing mostly includes non-literal meanings like idioms. Namely, when an utterance includes a swear word using body parts such as "to pluck your mustache out", it should not be interpreted literally; otherwise, it will lose its connotative meanings. Swearing users usually seek to use swearing in an attempt to inflict spiritual and psychological harm to the disputers while exchanging insults. The study revealed that swearwords are used to harm morally and emotionally the insulted person. Moreover, the study concluded that swearing is used to relieve the tension and anxiety of swearers. Jordanians are like any other nation in the world. They use swearing words to insult and hurt their disputers. In Jordan, young people are still using swear words in bitter disputes to protect themselves, diffuse their tension and cause harm to their disputers. Otherwise, it is surprising that swearers and disputers do not use swearing in exchanging insults. This linguistic phenomenon has become a register of life as well as a universal practice in the Jordanian setting. The study limits itself to a socio-pragmatic analysis of swearing using body parts in the Jordanian setting by male university students. Due to the important information that swearing may offer, the researchers recommend much more research studies be conducted in the future to examine the phenomenon of swearing using body parts by female university students in the Jordan setting.

\section{References}

[1] Andersson, L. \& Trudgill, P. (1990).Bad language (P.53). Oxford: Blackwell

[2] Anggita, F. (2015). "A sociolinguistic analysis of taboo words in bad teacher movie". Yogyakarta: Yogyakarta State University. (Published Thesis)

[3] Baudin, N. (2014).Swearing in English among a group of female Malaysian teenagers. International Journal of Contemporary Applied Sciences. (1) 3.

[4] Bungin, B. (2007). Social language (p. 107). Jakarta.Kencana Prenada Media Group.

[5] Brown, P. and Levinson, S. (1978). Universals in language usage: Politeness phenomenon. Question and politeness. Cambridge: Cambridge University Press.

[6] Burchfield, R. (1985). The English Language. Oxford: Oxford University Press 
[7] Holmes, J. (2001). An introduction to sociolinguistics (P.150). $2^{\text {nd }}$ edition. Person Education, England.

[8] Holmes, J. (2013). An introduction to sociolinguistics (p.283) (Fourth Edition). London \& New York: Routledge.

[9] Hudson, R. (1996). 2nd ed. Sociolinguistics (p. 16). Cambridge: Cambridge University Press

[10] Jay, T and Janschewitz, K. (2008). The pragmatics of swearing. Journal of Politeness Research, language, Behavior, Culture 4(2): $267-288$.

[11] Ljung, M. (2011). A cross-cultural linguistic study. London: Palgrave Macmillan.

[12] Oliver, F. (2011). Swearing and how to deal with it in the classroom. Final Thesis to a B.A. degree. The University of Iceland. Iceland.

[13] Montagu, A. (2001). The anatomy of swearing. Philadelphia, PA: University of Pennsylvania Press.

[14] Pinker, S. (2010). The stuff of thought: Language as a window into human nature. London: Penguin Books.

[15] Setiawan, S. and Fatima, T. (2018). Swear words among males: The social functions and pragmatic meaning. Advances in social science, Education and Humanities Research, (2)22. Universitas Negeri Surabaya Surabaya, Indonesia

[16] Sudaryanto, T. (1992).Methods of linguistics. Yogyakarta: Gadjah Mada University Press.

[17] Susetyaningsih, R.(2014). A sociolinguistic analysis of swearing uttered by the main character in the film the wolf of wall street (p.134). Yogyakarta State University, Malaysia. Published Ph.D. Thesis Study.

[18] Tannen, D.(1990). Gender differences in topical coherence: Creating involvement in best friends' talk. Discourse Processes, (1)3,73-90.

[19] Taufiq, Y. (2017). "The use of taboo words in war dogs movie (2016): A Sociopragmatic Study". Surakarta: Muhammadiyah University. MA Thesis.

[20] Wikipedia.(2019).Swearword. (Retrieved on 10 September, 2020) Web: https://www.google.com/search?biw=775\&bih=636\&ei=x40UXbGKMoyvrgSfk4WAAw\&q=wikipedia.+\%282015\%3A+online\%29.+swear+

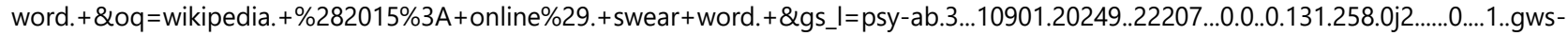
wiz.......0i71j35i39.2jjg2DhOXMI .

[21] Vanderstoep, S \& Johnston, D.(2009). Research methods for every life (p. 167).New York: John Wiley \& Sons

\section{Appendix(A)}

\section{Questionnaire}

\section{Dear respondent:}

This study attempts to investigate the phenomenon of swearing using body parts in the Jordanian community. So, it is hoped you objectively answer the following questions. Please respond to the questions below. Your response will be used for the study and confidentiality will be maintained.

Thanks for your response

A: General Information

Name :

Gender :

Age :

Nationality:

Major:

University Name:

B: Swearing -based questions

1. What body parts do you commonly use in swearing?

2. Why do you usually resort to swearing?

3. Do you mean what you say?

The End 


\section{Appendix(B)}

Illustrative examples of swearing using body parts

\begin{tabular}{|c|c|c|}
\hline No & Body part & Example \\
\hline 1 & Face & I will deform your face \\
\hline 2 & Head & I will chop off your head \\
\hline 3 & Mouth & Shut up your mouth \\
\hline 4 & Eyes & Damn your eyes \\
\hline 5 & Neck & I will break your neck \\
\hline 6 & Ears & I will bite your ears \\
\hline 7 & Teeth & I will make you swallow your teeth \\
\hline 8 & Mustache & I will clean the floor with your mustache \\
\hline 9 & Belly & I will step on your belly \\
\hline 10 & Hands & I will sprain your hand \\
\hline 11 & Tongue & I will pull out your tongue \\
\hline 12 & Head Hair & Your head hair is like a sweeper \\
\hline 13 & Beard & I will tread on your beard \\
\hline 14 & Throat & Shut up your throat \\
\hline 15 & Nose & I will break your nose \\
\hline 16 & Legs & I will cause paralysis in your leg \\
\hline 17 & Eyebrows & I will tear out your eyebrows \\
\hline 18 & Eyelashes & I will pull out your eyelashes \\
\hline 19 & Lips & Shut up your lips \\
\hline
\end{tabular}

